\title{
Electronic Health Records and the Increasing Complexity of Medical Practice
}

\author{
Rebecca $G$. Mishuris, MD, MS and Jeffrey A. Linder, MD, MPH \\ Division of General Medicine and Primary Care, Brigham and Women's Hospital, Boston, MA, USA.
}

J Gen Intern Med 28(11):1393

DOI: $10.1007 / \mathrm{s} 11606-013-2538-6$

(c) Society of General Internal Medicine 2013

To the Editors:-We read the Letter to the Editor by Drs. Kern and Kaushal regarding our Editorial and Comment on the use of electronic health records (EHRs) in health care nodding in agreement. ${ }^{1}$ EHRs are rapidly becoming ubiquitous, ${ }^{2}$ and their effect on quality is yet to be fully understood. It is vital that we study the impact of EHRs, be it neutral, positive, or negative.

Our only point of disagreement is what constitutes the "standard of care." EHR use has been essentially mandated. Three-quarters of physicians currently use an EHR, a $25 \%$ absolute increase from last year. ${ }^{2}$ EHRs are the standard of care.

That said, EHRs are far from perfect, and our new "standard" is anything but; there are over 200 certified EHRs available being variably implemented and used. It is imperative to study differences in EHRs and EHR use and stay focused on the ultimate goal of delivering high-value, high-quality care for our patients.

Corresponding Author: Jeffrey A. Linder, MD, MPH; Division of General Medicine and Primary Care, Brigham and Women's Hospital, 1620 Tremont Street, BC-3-2X, Boston, MA 02120, USA (e-mail: jlinder@partners.org).

\section{REFERENCES}

1. Mishuris RG, Linder JA. Electronic health records and the increasing complexity of medical practice: "it never gets easier, you just go faster". J Gen Intern Med. 2013;28:490-492.

2. Hsiao C-J, Hing E, National Center for Health Statistics (US). Use and characteristics of electronic health record systems among office-based physician practices, United States, 2001-2012. Hyattsville, MD: U.S. Dept. of Health and Human Services, Centers for Disease Control and Prevention, National Center for Health Statistics; 2012. 